\title{
Prevalence and Patterns of Obstructive Sleep Apnea in Asian Indians With Congestive Heart Failure
}

\author{
Sukriti Bhalla ${ }^{1}$, Kamal Sharma ${ }^{2}$, R D. Yadave ${ }^{3}$, Hardik D. Desai ${ }^{4}$, Tanisha Vora ${ }^{5}$, Erum Khan ${ }^{6}$, Purva \\ Shah $^{6}$, Dhigishaba Jadeja ${ }^{4}$, Vishal Bhandari ${ }^{7}$ \\ 1. Cardiology, Aakash Healthcare Super Specialty Hospital, New Delhi, IND 2. Cardiology, U.N. Mehta Institute of \\ Cardiology \& Research Centre, Ahmedabad, IND 3. Cardiology, Sri Balaji Action Medical Institute, New Delhi, IND 4. \\ Internal Medicine, Gujarat Adani Institute of Medical Sciences, Affiliated With Krantiguru Shyamji Krishna Verma \\ (KSKV) University, Bhuj, IND 5. Medical Education and Simulation, Smt. Nathiba Hargovandas Lakhmichand (NHL) \\ Municipal Medical College, Ahmedabad, IND 6. Medicine, Sir Byramjee Jeejeebhoy (BJ) Medical College, Ahmedabad, \\ IND 7. Interventional Cardiology, Tagore Hospital \& Heart Care Centre Private Limited, Jalandhar, IND
}

Corresponding author: Kamal Sharma, drkamalsharma@unmicrc.org

\section{Abstract}

\section{Background}

Sleep-disordered breathing (SDB) has a potential association with the pathogenesis of congestive heart failure (CHF). We assessed the prevalence and patterns of obstructive sleep apnea (OSA) in patients presenting with CHF.

\section{Method}

This was a prospective, observational, all-comers study of consecutive 77 confirmed cases of CHF. All these patients were clinically assessed and evaluated for OSA with sleep study after routine blood testing, electrocardiogram (ECG), chest X-ray, and echocardiography.

\section{Results}

Of 77 patients with CHF 38 (49.4\%) had apnea-hypopnea index (AHI) $<5$ while 39 (50.6\%) had AHI $>5$. Of these 39, 37 (94.8\%) patients showed the clinical features of OSA. The majority (64.9\%) of them were males. The majority of OSA (64.9\%) had coronary artery disease (CAD) $(\mathrm{p}<0.05)$ as the etiology of CHF, followed by dilated cardiomyopathy (32.4\%) and valvular heart disease (2.7\%). The prevalence of OSA was higher amongst New York Heart Association (NYHA) class 2 (51.4\%) as compared to NYHA class 3 (37.8\%) and NYHA class 4 (10.8\%). There were 12 (32.8\%) patients, each having OSA with a heart rate between 71 and $80 \mathrm{bpm}$ and 81 and $90 \mathrm{bpm}$. Twenty-two (59.5\%) had systolic blood pressure (BP) more than $120 \mathrm{mmHg}$ and 20 (54.1\%) had diastolic BP more than $80 \mathrm{mmHg}$. The majority (64.9\%) patients had the lowest $\mathrm{O}_{2}$ saturation between $80 \%$ and $90 \%$. A significantly large number of patients (62.2\%) had ejection fraction $21 \%-30 \%$ $(\mathrm{p}<0.05)$. The majority (62.16\%) of patients with OSA had AHI between 5 and 15. With 5-15 AHI, 20 (87\%)

Review began 10/05/2020 Review ended 10/29/2020 Published 11/11/2020

(c) Copyright 2020 Bhalla et al. This is an open access article distributed under the terms of the Creative Commons Attribution License CC-BY 4.0., which permits unrestricted use, distribution, and reproduction in any medium, provided the original author and source are credited. patients with OSA had a snoring, tiredness, observed apnea, high BP, BMI, age, neck circumference, and male gender (STOP-Bang) score between 3 and 7 with AHI 5-15 $(\mathrm{p}<0.05)$.

\section{Conclusions}

In our cohort, the prevalence of OSA in CHF was 50.6\%. Predictors of OSA in CHF were left ventricular ejection fraction (LVEF) 20\%-30\% and NYHA class 2. The majority had AHI between 5 and 15 . Sleep apnea screening should be routinely implemented in the evaluation and follow-up of heart failure patients.

Categories: Cardiology, Internal Medicine, Otolaryngology

Keywords: congestive heart failure, obstructive sleep apnea, apnea hypopnea index, asian indian

\section{Introduction}

Sleep-disordered breathing (SDB) is common in severe congestive heart failure (CHF), which comprises heart failure patients of low left ventricular ejection fraction (LVEF) and is associated with increased morbidity and mortality. Several pathophysiological mechanisms have also been suggested for the development of CHF in patients with obstructive sleep apnea (OSA) such as intermittent hypoxemia, elevated sympathetic activity secondary to recurrent arousals, and baroreflex inhibition. Apart from the etiological association, OSA could also have a higher prevalence in CHF [1-3]. One of the principal disorders with a recognized impact on cardiovascular function and disease is obstructive sleep apnea (OSA). Despite OSA being a risk factor for a cardiovascular disorder, the true prevalence of OSA amongst Asian Indians remains largely unknown, primarily because most people with OSA do not undergo polysomnography and hence may remain undiagnosed. 
Obstructive sleep apnea (OSA) is an important risk factor for the development of hypertension, angina pectoris, myocardial infarction, and cor pulmonale. Some recent data suggest that sleep apnea may also lead to the worsening of cardiac dysfunction in patients with CHF especially with heart failure with reduced ejection fraction (HFrEF).

The apnea-hypopnea index (AHI) is the average number of apneic and hypopneic events per hour of sleep, and it is the most common metric to describe the severity of OSA. OSA is said to be present when AHI is $>=5$ and is considered severe when $\mathrm{AHI}$ is $>=30$, with $\mathrm{AHI}<5$ ruling out OSA [4]. OSA is strongly associated with obesity, and there is a direct relationship between BMI and the AHI index [5]. OSA is present in over $40 \%$ of those with a body mass index (BMI) of 30, and it is especially common in individuals with a BMI of 40 .

CHF is a common serious problem in the world [6-8] and despite advances in pharmacotherapy, CHF continues to cause a significant burden of morbidity and mortality [7,9-10]. The prevalence of heart failure is estimated as $2 \%-3 \%$ of the adult population and increases with age [11]. Since SDB is common in patients with CHF, several studies have demonstrated increased mortality in CHF patients suffering from SDB in contrast to those without SDB.

Polysomnography (sleep study) is the gold standard test for the diagnosis of SDB, including OSA [12-13]. Split-night studies, in which the diagnostic study occurs during the first half of the night and continuous positive airway pressure (CPAP) titration occurs during the second half of the night, are increasingly used as a more cost-effective diagnostic-therapeutic strategy.

Targeting a common sleep disorder with treatment not only helps people with heart failure sleep better, but it can also make their hearts healthier. A new study shows that people who suffer from both CHF and OSA can benefit from a nighttime therapy designed to treat the sleep disorder known as CPAP [14].

The aim of this study is to assess the prevalence and patterns of OSA in Asian Indian patients with CHF with low LVEF.

\section{Materials And Methods}

This was a prospective, all-comers, observational study of consecutive CHF with reduced LVEF patients over a period of 12 months, with a total of 81 patients of CHF screened, out of which 77 patients completed the study. The study was conducted after obtaining institutional, departmental, and ethics committee clearances. Patients of either gender with symptoms of CHF with low LVEF, age 30-80 years, BMI $<25 \mathrm{~kg} / \mathrm{m}^{2}$, and LVEF $<45 \%$ were enrolled. Patients with a history of severe hepatic or renal disease, CVA, known case of OSA, malignancy, diabetes, and chronic obstructive pulmonary disease (COPD) were excluded from the study. Patients enrolled were clinically assessed and evaluated for CHF and OSA. Baseline characteristics were noted at the time of recruitment, and pulse and blood pressure measured just prior to polysomnography were captured. All the subjects underwent routine blood testing, electrocardiogram (ECG), chest X-ray, and echocardiography, followed by a sleep study (polysomnography). The snoring, tiredness, observed apnea, high BP, BMI, age, neck circumference, and male gender (STOP-Bang) score was used to correlate the extent of symptoms with $\mathrm{AHI}$ and other parameters of the severity of OSA.

\section{Statistical analysis}

The study was statistically analyzed using the Statistical Package for the Social Sciences (SPSS) software version 22 (IBM Corp., Armonk, NY). The qualitative variables were analyzed by the chi-square or Fisher's exact test and quantitative variables by expressing as mean or median and comparisons with a student's test.

\section{Results}

Eighty-one patients were screened according to the inclusion criteria in our study, but since four of them could not complete the sleep study, observations were captured and analyzed for the remaining 77 patients. Thirty-eight out of 77 patients (49.4\%) had AHI $<5$ while 39 had AHI $>=5$.

Table 1 shows the stratified frequency of AHI $<5$ and $>=5$ according to age and gender. The majority (35.1\%) of OSA patients with $\mathrm{AHI}>=5$ are aged above 70 , with 24 (64.9\%) males having $\mathrm{AHI}>=5$ and six $(75 \%)$ males having $\mathrm{AHI}<5$.

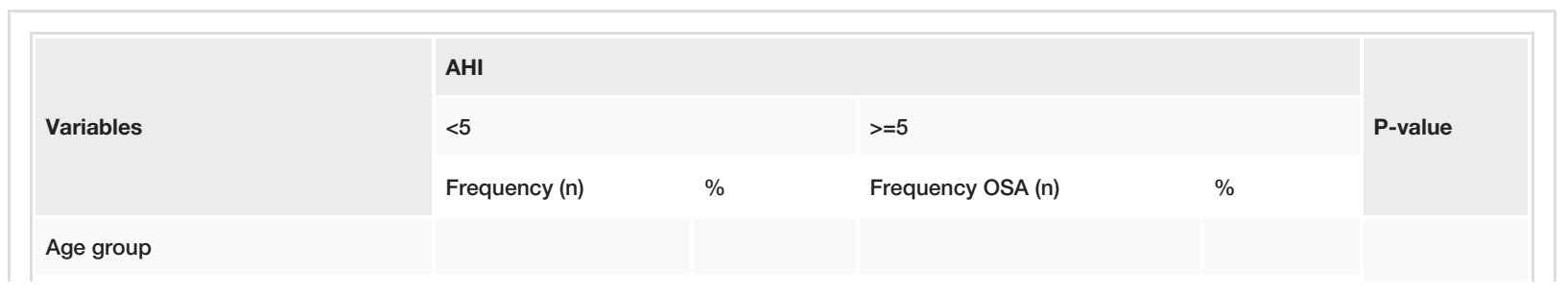




\section{Cureus}

\begin{tabular}{|c|c|c|c|c|c|}
\hline$<40 \mathrm{yrs}$ & 0 & $0.0 \%$ & 4 & $10.8 \%$ & \multirow{5}{*}{0.828} \\
\hline $41-50$ yrs & 1 & $12.5 \%$ & 6 & $16.2 \%$ & \\
\hline $51-60$ yrs & 2 & $25.0 \%$ & 9 & $24.3 \%$ & \\
\hline $61-70 \mathrm{yrs}$ & 2 & $25.0 \%$ & 5 & $13.5 \%$ & \\
\hline $71-80$ yrs & 3 & $37.5 \%$ & 13 & $35.1 \%$ & \\
\hline \multicolumn{6}{|l|}{ Sex } \\
\hline Male & 6 & $75.0 \%$ & 24 & $64.9 \%$ & \multirow{3}{*}{0.699} \\
\hline Female & 2 & $25.0 \%$ & 13 & $35.1 \%$ & \\
\hline \multicolumn{5}{|l|}{ Disease } & \\
\hline CAD & 6 & $75.0 \%$ & 24 & $64.9 \%$ & \multirow{4}{*}{0.022} \\
\hline DCMP & 0 & $0.0 \%$ & 12 & $32.4 \%$ & \\
\hline VALVULAR & 2 & $25.0 \%$ & 1 & $2.7 \%$ & \\
\hline Total & 8 & $100.0 \%$ & 37 & $100.0 \%$ & \\
\hline \multicolumn{6}{|l|}{ NYHA Class } \\
\hline II & 3 & $37.5 \%$ & 19 & $51.4 \%$ & \multirow{3}{*}{0.355} \\
\hline III & 5 & $62.5 \%$ & 14 & $37.8 \%$ & \\
\hline IV & 0 & $0.0 \%$ & 4 & $10.8 \%$ & \\
\hline \multicolumn{6}{|l|}{ Rhythm } \\
\hline NSR & 6 & $75.0 \%$ & 29 & $78.4 \%$ & \multirow{3}{*}{0.040} \\
\hline $\mathrm{AF}$ & 0 & $0.0 \%$ & 7 & $18.9 \%$ & \\
\hline LBBB & 2 & $25.0 \%$ & 1 & $2.7 \%$ & \\
\hline \multicolumn{6}{|l|}{$\mathrm{EF} \%$} \\
\hline$<20$ & 0 & $0.0 \%$ & 3 & $8.1 \%$ & \multirow{5}{*}{0.008} \\
\hline $20-30$ & 4 & $50.0 \%$ & 23 & $62.2 \%$ & \\
\hline $31-40$ & 3 & $37.5 \%$ & 11 & $29.7 \%$ & \\
\hline $41-45$ & 1 & $12.5 \%$ & 0 & $0.0 \%$ & \\
\hline \multicolumn{5}{|l|}{ Heart Rate } & \\
\hline$<=60$ & 0 & $0.0 \%$ & 0 & $0.0 \%$ & \multirow{6}{*}{0.206} \\
\hline $61-70$ & 0 & $0.0 \%$ & 4 & $10.8 \%$ & \\
\hline $71-80$ & 2 & $25.0 \%$ & 12 & $32.4 \%$ & \\
\hline $81-90$ & 6 & $75.0 \%$ & 12 & $32.4 \%$ & \\
\hline $91-100$ & 0 & $0.0 \%$ & 2 & $5.4 \%$ & \\
\hline$>100$ & 0 & $0.0 \%$ & 7 & $18.9 \%$ & \\
\hline \multicolumn{6}{|c|}{ SYSTOLIC BP mmHg } \\
\hline$<=110$ & 2 & $25.0 \%$ & 15 & $40.5 \%$ & \multirow{3}{*}{0.690} \\
\hline $111-119$ & 0 & $0.0 \%$ & 0 & $0.0 \%$ & \\
\hline$>=120$ & 6 & $75.0 \%$ & 22 & $59.5 \%$ & \\
\hline \multicolumn{6}{|c|}{ DIASTOLIC BP mmHg } \\
\hline$<=70$ & 6 & $75.0 \%$ & 17 & $45.9 \%$ & \\
\hline $71-79$ & 0 & $0.0 \%$ & 0 & $0.0 \%$ & 0.243 \\
\hline
\end{tabular}




\section{Cureus}

\begin{tabular}{|c|c|c|c|c|c|}
\hline$>=80$ & 2 & $25.0 \%$ & 20 & $54.1 \%$ & \\
\hline \multicolumn{6}{|c|}{ LOWEST O2 SAT \% } \\
\hline $70-79$ & 0 & $0.0 \%$ & 13 & $35.1 \%$ & \multirow{3}{*}{0.002} \\
\hline $80-89$ & 6 & $75.0 \%$ & 24 & $64.9 \%$ & \\
\hline $90-100$ & 2 & $25.0 \%$ & 0 & $0.0 \%$ & \\
\hline \multicolumn{6}{|c|}{ STOP-Bang Score } \\
\hline $0-2$ & 0 & $0.0 \%$ & 3 & $8.1 \%$ & \multirow{4}{*}{0.704} \\
\hline $3-4$ & 6 & $75.0 \%$ & 25 & $67.6 \%$ & \\
\hline $5-8$ & 2 & $25.0 \%$ & 9 & $24.3 \%$ & \\
\hline Total & 8 & $100.0 \%$ & 37 & $100.0 \%$ & \\
\hline
\end{tabular}

\section{TABLE 1: Stratified frequency of $A H I<5$ and $>=5$ according to 'demographics,' 'disease and clinical assessment and parameters,' and 'STOP-Bang score' among OSA patients}

AHI: apnea-hypopnea index, OSA: obstructive sleep apnea, CAD: coronary artery disease, DCMP: dilated cardiomyopathy, NYHA: New York Heart Association, NSR: normal sinus rhythm, LBBB: left bundle branch block, AF: atrial fibrillation, BP: blood pressure, STOP-Bang: snoring, tiredness, observed apnea, high BP, BMI, age, neck circumference, and male gender

Table 1 shows that the frequency of OSA was found to be the most, i.e. 24 (64.9\%), in CAD patients followed by 12 (32.4\%) patients with dilated cardiomyopathy (DCMP), and only a single patient with OSA had valvular heart disease. The $\mathrm{P}$-value for the etiology difference amongst OSA in CHF was significant $(\mathrm{P}<0.05)$. More patients were found to have $\mathrm{CAD}$ in patients with $\mathrm{AHI}>=5$ amongst CHF.

OSA was a maximum of $19(51.4 \%)$ in NYHA class 2 patients as compared to only 14 (37.8\%) patients with NYHA class 3 and 4 (10.8\%) patients in NYHA class 4 group. Twenty-nine (78.4\%) OSA patients had normal sinus rhythm (NSR), atrial fibrillation (AF) was present in seven (18.9\%) OSA patients, and only a single patient had LBBB. There was a significantly greater number of patients with NSR $(\mathrm{p}<0.05)$

Table 1 also shows that a larger number of patients, i.e. 23 (62.2\%) with OSA frequency had EF 21\%-30\% while 11 (29.7\%) OSA patients had EF (\%) 31-40\%. Only three (8.1\%) OSA had EF $(\%)<20(p<0.05)$. A significantly greater number of patients were found to have $\mathrm{EF}(\%)$ between 21 and 30.

Table 1 gives clinical parameters stratified by AHI. It shows that the same number of patients, i.e., 12 in each group (32.4\%) with a heart rate between 71 and $80 \mathrm{bpm}$ and 81 and $90 \mathrm{bpm}$, respectively, had the highest OSA frequency. Twenty-two (59.5\%) patients with OSA had systolic BP $>=120$ while 15 (40.5\%) patients had systolic BP $<=110 \mathrm{mmHg}$. 20 patients $(54.1 \%)$ with OSA had $>=80 \mathrm{mmHg}$ diastolic BP while 17 (45.9\%) had diastolic $\mathrm{BP}<=70$. A significant number of patients with OSA had the lowest measured $\mathrm{O}_{2}$ saturation of $80 \%-89 \%(\mathrm{p}<0.05)$.

Table 1 shows that 25 (67.6\%) patients with OSA had a STOP-Bang score of 3-4, nine (24.3\%) OSA patients had a STOP-Bang score of 5-8, and only three (8.1\%) OSA patients had a STOP-Band score of 0-2.

Our study shows a variation in AHI, i.e. mild ( 5 to $<15)$, moderate $(15$ to $<30)$, and severe $(>30)$, therefore, an analysis was done to find the prevalence of OSA in relation to the severity of AHI. The majority, i.e. 23 patients with OSA had AHI between 5 and 15, of which the maximum belonged to the 51-60 year age group. Similarly, males had higher frequencies of OSA (Table 2). Patients with CAD showed maximum OSA in all severity groups followed by DCMP, OSA frequency declined from NYHA class 2 to 4 in AHI 5-15. In AHI 5-15, OSA (65.2\%) was most frequent in patients with EF 20-30\% (Table 2)

\begin{tabular}{|c|c|c|c|c|}
\hline \multirow{3}{*}{ Variables } & \multicolumn{3}{|l|}{ AHI Groups } & \multirow{3}{*}{ P-value } \\
\hline & 5 to $<15$ & 15 to $<30$ & $>30$ & \\
\hline & Frequency OSA (\%) & Frequency OSA (\%) & Frequency OSA (\%) & \\
\hline
\end{tabular}




\section{Cureus}

\begin{tabular}{|c|c|c|c|c|}
\hline \multicolumn{5}{|l|}{ Age Groups } \\
\hline$<40 \mathrm{yrs}$ & $2(8.7 \%)$ & $2(22.2 \%)$ & $0(0 \%)$ & \multirow{3}{*}{0.173} \\
\hline $41-50$ yrs & 4 (17.4\%) & $2(22.2 \%)$ & $0(0 \%)$ & \\
\hline $51-60 \mathrm{yrs}$ & $8(34.8 \%)$ & $1(11.1 \%)$ & $0(0 \%)$ & \\
\hline $61-70 \mathrm{yrs}$ & 4 (17.4\%) & $0(0 \%)$ & $1(20.0 \%)$ & \\
\hline $71-80$ yrs & 5 (21.7\%) & 4 (44.4\%) & 4 (80.0\%) & \\
\hline \multicolumn{5}{|l|}{ Sex } \\
\hline Male & $14(60.9 \%)$ & $6(66.7 \%)$ & $4(80.0 \%)$ & \multirow{2}{*}{0.713} \\
\hline Female & 9 (39.1\%) & 3 (33.3\%) & 1 (20.0\%) & \\
\hline \multicolumn{5}{|l|}{ Disease } \\
\hline CAD & 16 (69.6\%) & $4(44.4 \%)$ & $4(80.0 \%)$ & \multirow{3}{*}{0.330} \\
\hline DCMP & 7 (30.4\%) & $4(44.4 \%)$ & $1(20.0 \%)$ & \\
\hline VALVULAR & $0(0 \%)$ & $1(11.1 \%)$ & $0(0 \%)$ & \\
\hline \multicolumn{5}{|l|}{ NYHA Class } \\
\hline II & 14 (60.9\%) & $2(22.2 \%)$ & $3(60.0 \%)$ & \multirow{3}{*}{0.312} \\
\hline III & $7(30.4 \%)$ & 5 (55.6\%) & $2(40.0 \%)$ & \\
\hline IV & $2(8.7 \%)$ & 2 (22.2\%) & $0(0 \%)$ & \\
\hline \multicolumn{5}{|l|}{ Rhythm } \\
\hline NSR & 19 (82.6\%) & $6(66.7 \%)$ & $4(80.0 \%)$ & \multirow{3}{*}{0.693} \\
\hline $\mathrm{AF}$ & $3(13.0 \%)$ & $3(33.3 \%)$ & $1(20.0 \%)$ & \\
\hline LBBB & $1(4.3 \%)$ & $0(0 \%)$ & $0(0 \%)$ & \\
\hline \multicolumn{5}{|l|}{ EF\% } \\
\hline$<20$ & $2(8.7 \%)$ & $1(11.1 \%)$ & $0(0 \%)$ & \multirow{4}{*}{0.703} \\
\hline $21-30$ & $15(65.2 \%)$ & 4 (44.4\%) & $4(80.0 \%)$ & \\
\hline $31-40$ & $6(26.1 \%)$ & $4(44.4 \%)$ & $1(20.0 \%)$ & \\
\hline $41-45$ & $0(0 \%)$ & $0(0 \%)$ & $0(0 \%)$ & \\
\hline \multicolumn{5}{|c|}{ STOP-Bang Score } \\
\hline $0-2$ & $1(4.3 \%)$ & $2(22.2 \%)$ & $0(0 \%)$ & \multirow{4}{*}{0.009} \\
\hline $3-7$ & $20(87.0 \%)$ & $2(22.2 \%)$ & $3(60.0 \%)$ & \\
\hline $5-8$ & $2(8.7 \%)$ & 5 (55.6\%) & $2(40.0 \%)$ & \\
\hline Total & $23(100 \%)$ & $9(100 \%)$ & $5(100 \%)$ & \\
\hline \multicolumn{5}{|l|}{$\mathrm{HR}$} \\
\hline $61-70$ & $3(13.0 \%)$ & $1(11.1 \%)$ & $0(0 \%)$ & \\
\hline $71-80$ & 10 (43.5\%) & $0(0 \%)$ & $2(40.0 \%)$ & \\
\hline $81-90$ & $7(30.4 \%)$ & 3 (33.3\%) & 2 (40.0\%) & 0.274 \\
\hline
\end{tabular}




\section{Cureus}

\begin{tabular}{|c|c|c|c|c|}
\hline $91-100$ & $1(4.3 \%)$ & $1(11.1 \%)$ & $0(0 \%)$ & \\
\hline$>100$ & $2(8.7 \%)$ & 4 (44.4\%) & $1(20.0 \%)$ & \\
\hline \multicolumn{5}{|c|}{ SYSTOLIC BP mmHg } \\
\hline$<=110$ & $11(47.8 \%)$ & 3 (33.3\%) & $1(20.0 \%)$ & \multirow{3}{*}{0.455} \\
\hline $111-119$ & $0(0 \%)$ & $0(0 \%)$ & $0(0 \%)$ & \\
\hline$>=120$ & $12(52.2 \%)$ & $6(66.7 \%)$ & $4(80.0 \%)$ & \\
\hline \multicolumn{5}{|c|}{ DIASTOLIC BP mmHg } \\
\hline$<=70$ & $11(47.8 \%)$ & $5(55.6 \%)$ & $1(20.0 \%)$ & \multirow{3}{*}{0.423} \\
\hline $71-79$ & $0(0 \%)$ & $0(0 \%)$ & $0(0 \%)$ & \\
\hline$>=80$ & $12(52.2 \%)$ & $4(44.4 \%)$ & $4(80.0 \%)$ & \\
\hline \multicolumn{5}{|c|}{ LOWEST O2 SAT \% } \\
\hline $70-79$ & $6(26.1 \%)$ & $2(22.2 \%)$ & $5(100 \%)$ & \multirow{3}{*}{0.005} \\
\hline $80-89$ & $17(73.9 \%)$ & $7(77.8 \%)$ & $0(0.0 \%)$ & \\
\hline $90-100$ & $0(0.0 \%)$ & $0(0.0 \%)$ & $0(0.0 \%)$ & \\
\hline
\end{tabular}

\section{TABLE 2: Stratified frequency of AHI severity according to 'demographics,' 'disease and clinical assessment and parameters,' and 'STOP-Bang score' among OSA patients}

AHI: apnea-hypopnea index, OSA: obstructive sleep apnea, CAD: coronary artery disease, DCMP: dilated cardiomyopathy, NYHA: New York Heart Association, NSR: normal sinus rhythm, LBBB: left bundle branch block, AF: atrial fibrillation, BP: blood pressure

OSA frequency was higher in patients with NSR with heart rates 70-80 bpm and 81-90 bpm with high systolic BP (>=120 $\mathrm{mm} \mathrm{Hg}$ ) and diastolic BP (>=80 mm Hg) though these findings did not reach statistical significance. The highest frequency of OSA patients was seen in those with their lowest oxygen saturation between $80 \%$ and $90 \%$. (Table 2).

Table 2 showed that most OSA patients, i.e. 20 (87.0\%) had a STOP-Bang score of 3-5 and fell into the category AHI 5 to $<15$. There were five (55.5\%) OSA patients who had a STOP-Bang score of 5-8 and fell in the category AHI 15 to $<30(\mathrm{p}<0.05)$.

\section{Discussion}

In our study, we found that a significant number of patients (39) with CHF with reduced LVEF had AHI value $>5$. Out of 77 total investigated patients, 45 (58.4\%) showed the presence of symptoms of OSA. Thirty-nine (50.6\%) had AHI >=5; out of those, 37 (94.8\%) showed the presence of the clinical findings of OSA. A high prevalence of SDB amongst the male cohort of CHF with low LVEF was seen in our study; out of 37 patients, OSA was present in 24 males (64.9\%) as compared to 13 females (35.1\%) (Table 1). These results are consistent with an overall estimation across different countries where the prevalence of SDB is approximately $3 \%$ to $7 \%$ for adult men and $2 \%$ to $5 \%$ for adult women in the general population [15].

Javaheri et al. investigated 81 outpatients with stable heart failure, defined as an LVEF of $45 \%$. Most of these patients $(75 \%)$ had CAD; the remainder had cardiomyopathies. Using an AHI threshold of $\geqslant 15 / \mathrm{h}$, the authors found relevant SDB in 41 patients (51\%) [16], which is consistent with our data. However, the vast majority of Javaheri's patients had CSA (40\%); only $11 \%$ had OSA. Although there are important physiological differences between the two, OSA and CSA may often coexist, particularly in patients with heart failure. The results in our study differed and showed that the vast majority of patients had OSA (58.4\%) and AHI > $=5$ in $50.6 \%$.

The results in our study showed that the majority of the patients had NYHA class 2 (Table 1) and had worse LVEF (Table 1). The findings of our study are consistent with a large retrospective analysis of SDB in symptomatic CHF (AHI $\geqslant 15 / \mathrm{h}$, NYHA class $\geqslant 2$, LVEF $27.3 \pm 15.6 \%$ ) by Sin et al. who reported a $61 \%$ prevalence of SDB, including CSA in $29 \%$ and OSA in $32 \%$ [17]. Our findings are similar, where $47 \%$ of the patients had OSA and 33\% had CSA; patients with OSA belonged to the severity range of 5 to 15 .

There was a significant number of patients with NSR, which does not correspond to the results of previous studies [17-18] that have reported a higher incidence of AF. OSA is associated with significant atrial 
remodeling characterized by atrial enlargement, reduction in voltage, site-specific and widespread conduction abnormalities, and longer sinus node recovery. These features may, in part, explain the association between OSA and AF [19].

Population-based studies have estimated that one in five middle-aged Western adults, with a BMI of 25 to $28 \mathrm{~kg} / \mathrm{m}^{2}$ have OSA, and one in 20 are symptomatic, with the OSA syndrome [20]. OSA is strongly associated with obesity, and there is a direct relationship between BMI and the AHI index [4]. In our study, OSA was studied in persons with a normal BMI of 18.5-24.9. OSA is highly prevalent in patients with cardiovascular disease and is independently associated with metabolic syndrome in classical symptomatic SDB patients [21]. Therefore, a high body mass index and a trend towards a higher prevalence of diabetes would be expected for CHF with low LVEF patients with OSA [17].

In the present study, OSA has been found to be prevalent in patients with CHF as shown in Table 1 . This is consistent with other workers who have reported that with respect to cardiac function, OSA might be a cause of daytime systolic LV dysfunction, which may resolve following effective continuous positive airway pressure (CPAP) therapy [22-25]. Even in adults with normal resting LV function, OSA is associated with an impaired response (increase in cardiac output and stroke volume) to exercise, with CPAP therapy being able to reverse this response. This suggests that pathophysiological changes associated with OSA over the years might progress into structural ventricular damage and lead to symptomatic heart failure. Therefore, OSA might be related to both the causation and progression of heart failure [26]. This is consistent with our findings where the frequency of OSA is more in patients with CHF. So far, it is proven that OSA is an independent risk factor for fatal and non-fatal cardiovascular events [4] and all-cause mortality [27].

Sleep apnea appears to be associated with heart disease regardless of the presence of high blood pressure or other heart risk factors. Studies suggest that patients with moderate-to-severe obstructive sleep apnea have a higher risk of a heart attack.

In the present study, the severity of SDB, when assessed by AHI, in a significant number of OSA patients had the lowest $\mathrm{O} 2$ saturation of $80 \%-90 \%$ and belonged to AHI groups 5 to $<15$ (Table 2). In this context, Sin et al. reported differences in parameters indicative for central and obstructive sleep-disordered breathing events, but the overall mean AHI was not statistically different [17].

\section{Limitations}

There are some potential limitations to our study. First, we evaluated SDB by the Special ResMed's ApneaLink $^{\mathrm{TM}}$ Air device [28] and not by complete lab polysomnography. As a consequence, the prevalence and degree of SDB might even be higher than the actual in our cohort of CHF patients. Another limitation may be the fact that the prevalence of SDB in our hospital, which is a tertiary academic cardiac care unit, may be higher than community hospitals. On the other hand, this might also reflect the true prevalence of SDB in symptomatic and severe heart failure. Other studies used patients who were on medication and were obese or overweight, which were not selected for our study. The sample size of our study was also small.

Evidence is lacking to address OSA as a risk factor of CAD or as a prognostic factor of CAD, and more evidence is needed to address CPAP treatment as a useful therapy for patients with CAD and nonsymptomatic OSA [29]. However, research in this field is growing rapidly, and data answering some of these questions may soon be available.

\section{Conclusions}

A high prevalence of SDB was found in Asian Indian patients with symptomatic CHF with reduced LVEF, especially amongst males. The prevalence of OSA was highest in CHF patients with LVEF 20\%-30\% and amongst those with NYHA class I2. A relationship was also found between low EF \% and high OSA frequency with $\mathrm{AHI}>=5$. CAD was the most common etiology of CHF, with reduced LVEF in patients who had OSA. The lowest $\mathrm{O} 2$ saturation range of $80 \%-89 \%$ was most frequently observed during the sleep study. Also, a significant number of patients with OSA had the lowest $\mathrm{O}_{2}$ saturation of $80 \%-90 \%$ and belonged to AHI 5 to 15 (mild category). More research with bigger sample size is required to find out the association of sleep apnea and CHF, especially with titration studies, and the effect of CPAP treatment on such patients outcomes.

\section{Additional Information \\ Disclosures}

Human subjects: Consent was obtained by all participants in this study. Shree Balaji Action Medical Institute, New Delhi issued approval SBAMI-EC/2014/16. This study was approved by the Institutional Ethical Committee. IRB approval number: SBAMI-EC/2014/16. Animal subjects: All authors have confirmed that this study did not involve animal subjects or tissue. Conflicts of interest: In compliance with the ICMJE uniform disclosure form, all authors declare the following: Payment/services info: All authors have 
declared that no financial support was received from any organization for the submitted work. Financial relationships: All authors have declared that they have no financial relationships at present or within the previous three years with any organizations that might have an interest in the submitted work. Other relationships: All authors have declared that there are no other relationships or activities that could appear to have influenced the submitted work.

\section{References}

1. Levy P, Pepin J, Arnaud C, et al.: Intermittent hypoxia and sleep-disordered breathing: current concepts and perspectives. Eur Respir J. 2008, 32:1082-1095. 10.1183/09031936.00013308

2. Mansfield D, Kaye DM, La Rocca HB, Solin P, Esler MD, Naughton MT: Raised sympathetic nerve activity in heart failure and central sleep apnea is due to heart failure severity. Circulation. 2003, 107:1396-1400. 10.1161/01.cir.0000056520.17353.4f

3. Sforza E, Martin MS, Barthélémy JC, Roche F: Is there an association between altered baroreceptor sensitivity and obstructive sleep apnoea in the healthy elderly?. ERJ Open Res. 2016, 2:00072. 10.1183/23120541.00072-2016

4. Marin JM, Carrizo SJ, Vicente E, Agusti AG: Long-term cardiovascular outcomes in men with obstructive sleep apnoea-hypopnoea with or without treatment with continuous positive airway pressure: an observational study. Lancet. 2005, 365:1046-1053. 10.1016/S0140-6736(05)71141-7

5. Gami AS, Caples SM, Somers VK: Obesity and obstructive sleep apnea. Endocrinol Metab Clin North Am. 2003, 32:869-894. 10.1016/S0889-8529(03)00069-0

6. McMurray J, Stewart S: Epidemiology, aetiology and prognosis of heart failure. Heart. 2000, 83:596-602. 10.1136/heart.83.5.596

7. Ho KK, Pinsky JL, Kannel WB, Levy D: The epidemiology of heart failure: the Framingham study . J Am Coll Cardiol. 1993, 22:6-13. 10.1016/0735-1097(93)90455-A

8. Cowie MR, Wood DA, Coats AJ, Thompson SG, Poole-Wilson PA, Suresh V, Sutton GC: Incidence and aetiology of heart failure; a population-based study. Eur Heart J. 1999, 20:421-428. 10.1053/euhj.1998.1280

9. The CONSENSUS Trial Study Group: Effects of enalapril on mortality in congestive heart failure: results of the cooperative North Scandinavian enalapril survival study (CONSENSUS). N Engl J Med. 1987, 316:14291435. 10.1056/nejm198706043162301

10. The SOLVD Investigators: Effect of enalapril on survival in patients with reduced left ventricular ejection fractions and congestive heart failure. N Engl J Med. 1991, 325:293-302. 10.1056/NEJM199108013250501

11. Collop NA: Portable monitoring for the diagnosis of obstructive sleep apnoea. Curr Opin Pulm Med. 2008, 14:525-529. 10.1097/MCP.0b013e328312ed4a

12. Boyer S, Kapur V: Role of portable sleep studies for diagnosis of obstructive sleep apnea . Curr Opin Pulm Med. 2003, 9:465-470.

13. Kanoko Y, Floras J, Usui K, et al.: Cardiovascular effects of continuous positive airway pressure in patients with heart failure and obstructive sleep apnea. N Engl J Med. 2003, 348:1233-1241. 10.1056/NEJMoa022479

14. Savarese G, Lund LH: Global public burden of heart failure . Heart Fail Rev. 217, 3:7-11. 10.15420/cfr.2016:25:2

15. Punjabi NM: The epidemiology of adult obstructive sleep apnea. Proc Am Thorac Soc. 2008, 5:136-143.

16. Javaheri S, Parker TJ, Liming JD, Corbett WS, Nishiyama H, Wexler L, Roselle GA: Sleep apnea in 81 ambulatory male patients with stable heart failure. Types and their prevalences, consequences and presentations. Circulation. 1998, 97:2154-2159. 10.1161/01.CIR.97.21.2154

17. Sin DD, Fitzgerald F, Parker JD, Newton G, Floras JS, Bradley TD: Risk factors for central and obstructive sleep apnea in 450 men and women with congestive heart failure. Am J Respir Crit Care Med. 1999, 160:1101-1106. 10.1164/ajrccm.160.4.9903020

18. Ferrier K, Campbell A, Yee B, Richards M, O’Meeghan T, Weatherall M, Neill A: Sleep-disordered breathing occurs frequently in stable outpatients with congestive heart failure. Chest. 2005, 128:2116-2122. 10.1378/chest.128.4.2116

19. Dimitri H, Ng M, Brooks AG, Kuklik P, Stiles MK, Lau DH, Antic N: Atrial remodeling in obstructive sleep apnea: implications for atrial fibrillation. Heart Rhythm. 2011, 9:321-327. 10.1016/j.hrthm.2011.10.017

20. Jamie CM, Lam SK, Sharma, Lam B: Obstructive sleep apnoea: definitions, epidemiology and natural history. Indian J Med Res. 2010, 131:165-170.

21. Coughlin S, Mawdsley L, Mugarza J, Calverley P, Wilding J: Obstructive sleep apnoea is independently associated with an increased prevalence of metabolic syndrome. Eur Heart J. 2004, 25:735-741. 10.1016/i.ehj.2004.02.021

22. Kaneko Y, Floras JS, Usui K, et al.: Cardiovascular effects of continuous positive airway pressure in patients with heart failure and obstructive sleep apnea. N Engl J Med. 2003, 348:1233-1241. 10.1056/NEJMoa022479

23. Vasu TS, Doghramji K, Cavallazzi R, et al.: Obstructive sleep apnea syndrome and prospective complications. Clinical use of the STOP-BANG questionnaire. Arch Otolaryngol Head Neck Surg. 2010, 136:1020-1024. 10.1001/archoto.2010.1020

24. Alonso-Fernández A, Garcia-Rio F, Arias MA, Mediano O, Pino JM, Martínez I, Villamor J: Obstructive sleep apnoea-hypoapnoea syndrome reversibly depresses cardiac response to exercise. Eur Heart J. 2006, 27:207215. 10.1093/eurheartj/ehi621

25. Mansfield DR, Gollogly NC, Kaye DM, Richardson M, Bergin P, Naughton MT: Controlled trial of continuous positive airway pressure in obstructive sleep apnea and heart failure. Am J Respir Crit Care Med. 2004, 169:361-6. 10.1164/rccm.200306-7520C

26. Mansfield D, Naughton MT: Obstructive sleep apnoea, congestive heart failure and cardiovascular disease . Heart Lung Circ. 2005, 14:2-7. 10.1016/j.hlc.2005.08.010

27. Yaggi HK, Concato J, Kernan WN, Lichtman JH, Brass LM, Mohsenin V: Obstructive sleep apnea as a risk factor for stroke and death. N Engl J Med. 2005, 353:2034-2041. 10.1056/NEJMoa043104

28. Laaban JP, Pascal-Sebaoun S, Bloch E, Orvoën-Frija E, Oppert JM, Huchon G: Left ventricular systolic dysfunction in patients with obstructive sleep apnea syndrome. Chest. 2002, 122:1133-8. 


\section{Cureus}

10.1378/chest.122.4.1133

29. De Torres-Alba F, Gemma D, Armada-Romero E, Rey-Blas JR, López-de-Sá E, López-Sendon JL: Obstructive sleep apnea and coronary artery disease: from pathophysiology to clinical implications. Pulm Med. 2013, 2013:768064. 10.1155/2013/768064 